\title{
The Role of Formylpeptide Receptors, C5a Receptors, and Cytosolic-Free Calcium in Neutrophil Priming
}

\author{
Werner Zimmerli, Anne-Marie Reber, \\ and Clemens A. Dahinden
}

\begin{abstract}
From the Departments of Medicine and Research, University Hospital, Basel, and the Institute for Clinical Immunology, University Hospital,
\end{abstract}

Bern, Switzerland

\begin{abstract}
Polymorphonuclear leukocytes (PMNL) exposed to chemoattractants or cytokines change their functional capacity. The effect of endotoxin-activated serum as a priming agent on human PMNL was tested. Pretreatment of PMNL with endotoxin-activated serum increased their oxidative burst in response to formylpeptide (FMLP) $(P<.02)$ and $C 5 a(P<.05)$. Priming for membrane depolarization was observed in PMNL preincubated with either endotoxin-activated serum, low concentrations of purified C5a, or endotoxin but not with decomplemented plasma. Primed PMNL had an increased number of FMLP but not C5a receptors as compared with control PMNL. The "resting" cytosolic free calcium was increased in primed PMNL $(P<.02)$. Intracellular calcium buffering abolished the priming effect of endotoxin-activated serum. Thus, endotoxin-activated serum can prime cellular responsiveness for membrane depolarization and superoxide production in response to FMLP and to C5a. Priming may be due to an increased resting cytosolic-free calcium.
\end{abstract}

Polymorphonuclear leukocytes (PMNL) are end-stage cells that play an important role in host defense and inflammation [1]. Upon exposure to chemoattractants, they are capable of improving their functional capacity [2]. Immature PMNL such as those from patients with myelodysplastic syndromes or leukemia have functional defects $[3,4]$. In contrast, extravascular PMNL, that is, those in an advanced life stage, have an increased responsiveness to $\mathrm{N}$-formylmethionylleucylphenylalanine (FMLP) compared to blood PMNL from the same species [2]. The exact mechanisms of this functional improvement (priming) are unknown but may at least be partially due to FMLP-receptor upregulation [2].

In this study we analyzed the effect of prestimulation of human PMNL in vitro on their subsequent responsiveness. The phenomenon of priming was investigated by incubating PMNL with either endotoxin-activated serum (EAS) or some of its components, namely endotoxin, C5a, and decomplemented plasma. EAS was used because it most closely simulates the clinical situation of gram-negative sepsis, during which PMNL may be primed. The importance of migration in the cellular priming was analyzed by using a chemotactic chamber as an in vitro model of locomotion. Cellular responsiveness of EASpretreated PMNL to FMLP and purified C5a was measured. The mechanisms of priming were analyzed in terms of FMLP-

Received 10 January 1989; revised 5 September 1989.

Published in part as an abstract in Eur J Clin Invest 1987;17:A64.

Supported by grant 3.811-086 and a career development award (to W. Z.) from the Swiss National Science Foundation.

Reprints and correspondence: Dr. Werner Zimmerli, Departments of Medicine and Research, University Hospital, CH-4031 Basel, Switzerland.

The Journal of Infectious Diseases 1990;161:242-249 (c) 1990 by The University of Chicago. All rights reserved. $0022-1899 / 90 / 6102-0014 \$ 01.00$ and C5a-receptor studies. Because not every priming could be explained by receptor upregulation, we investigated whether an increased "resting" cytosolic-free calcium $\left(\left[\mathrm{Ca}^{2+}\right]_{i}\right)$ could be involved.

\section{Materials and Methods}

Reagents. Reagents used and their sources were: bovine serum albumin, cytochalasin B, cytochrome C (type IV), dimethyl sulfoxide, HEPES, FMLP, phenolphthalein glucuronic acid solution, phenolphthalein, phenolphthalein standard solution, phorbol myristate acetate (PMA), quin 2 acetoxymethylester (quin 2-AM), quin 2 free acid, and triton X-100 (Sigma Chemical, St. Louis); dextran T-500 and Percoll (Pharmacia Fine Chemicals, Uppsala, Sweden); endotoxin lipopolysaccharide-B Escherichia coli O26 (Difco Laboratories, Detroit); ${ }^{57} \mathrm{Co}-\mathrm{B} 12$ and FML $\left[{ }^{3} \mathrm{H}\right] \mathrm{P}$ (specific activity 60 $\mathrm{Ci} / \mathrm{mmol}$; New England Nuclear, Boston); EDTA and activated charcoal (Merck AG, Zurich); polymyxin B and ionomycin (Calbiochem, San Diego); 3,3'-dipentyloxacarbocyanine iodide (di-O-C5(3); Molecular Probes, Junction City, OR), and Harleco Diff-Quik (Merz \& Dade AG, Düdingen, Switzerland). HEPES-Hanks' balanced salt solutions with (HBSS) or without calcium and magnesium (mHBSS) were prepared according to standard methods [5]. FMLP, PMA, and EAS were prepared as described by Metcalf et al. [5].

Isolation of PMNL. Human blood PMNL were purified from EDTA-anticoagulated ( $5 \mathrm{mM}$ final concentration) blood, drawn by venipuncture from healthy human volunteers. Purification included dextran T-500 (3\% in $0.9 \%$ saline) sedimentation and subsequent centrifugation $\left(350 \mathrm{~g}\right.$ for $30 \mathrm{~min}$ at $4^{\circ} \mathrm{C}$ ) on a $53 \% / 67 \%$ Percoll gradient, similar to that previously described $[2,6]$. PMNL accumulating at the interphase of the gradient were washed twice in $0.9 \%$ saline. Hypotonic lysis was performed, if necessary, with distilled water and correction of the osmolarity with $1.8 \% \mathrm{NaCl}$ after $15-30 \mathrm{~s}$.

Pretreatment of PMNL in vitro. Purified PMNL ( $>98 \%$ pure) were suspended in HBSS supplemented with $0.1 \%$ glucose and $0.1 \%$ bovine serum albumin at a concentration of $1 \times 10^{7} \mathrm{PMNL} / \mathrm{ml}$. 
The priming agents were added in different concentrations (see Results). Incubations were performed in Falcon plastic tubes (Becton Dickinson, Oxnard, CA) on an overhead rotator at $37^{\circ} \mathrm{C}$, and terminated after $30 \mathrm{~min}$ by adding ice-cold mHBSS. Pretreated PMNL were washed twice with mHBSS and then resuspended at $10^{7}$ $\mathrm{PMNL} / \mathrm{ml}$ for use in the functional assays. Migrated PMNL (CTXEAS-PMNL) wene washed away from the lower part of a 10- $\mu \mathrm{m}$ thick, $5-\mu \mathrm{m}$ pore diameter chemotaxis filter (Nucleopore, Pleasanton, CA), and from the lower wells of a chemotaxis microchamber (Neuro Probe, Cabin John, MD) containing 1.7\% EAS. These PMNL, which migrated through the filter within $30 \mathrm{~min}$, were washed twice before use in the functional assays. Control PMNL were incubated in HBSS $/ 0.1 \%$ glucose $/ 0.1 \%$ albumin alone.

Control experiments. Endotoxin modulates PMNL functions at low concentrations [7-11]. Therefore, any solution used for the purification and preincubation procedure was tested for its endotoxin contamination by the amoebocyte lysate assay (Pyrogel; Skan AG, Basel, Switzerland). $\mathrm{H}_{2} \mathrm{O}$, saline, EDTA, dextran, and $\mathrm{C5a}\left(10^{-9} M\right)$ contained $<1 \mathrm{ng} / \mathrm{ml}$ endotoxin. HBSS-albumin and Percoll ( $53 \%$ and $67 \%$ ) had an endotoxin contamination of $<100 \mathrm{ng} / \mathrm{ml}$. Since polymyxin $B$ binds endotoxin, we compared PMNL preparations isolated in either the presence or absence of polymyxin B $(10 \mu \mathrm{g} / \mathrm{ml})$ [12]. The priming effect of endotoxin $(5 \mu \mathrm{g} / \mathrm{ml})$ in the superoxide assay was identical in the two different PMNL preparations (data not shown).

Membrane potential. Membrane potential was determined in a fluorescence spectrophotometer (LS5; Perkin-Elmer, Norwalk, CT) with the fluorescent probe di-O-C5(3) as previously described [13].

Superoxide production. Superoxide $\left(\mathrm{O}_{2}^{-}\right)$production was determined at $37^{\circ} \mathrm{C}$ spectrophotometrically (550 nm, mM extinction coefficient of $21,100 \mathrm{M}^{-1} \mathrm{~cm}^{-1}$ ) by continuously monitoring the $\mathrm{O}_{2}^{-}-$ dismutase ( 300 units $/ \mathrm{ml}$ )-inhibitable reduction of cytochrome-C (120 $\mu \mathrm{g} / \mathrm{ml}$ ) in a double-beam spectrophotometer (model 35, Beckman Instruments, Fullerton, $\mathrm{CA}$ ) with a temperature regulator set, as described previously [6].

C5a purification and labeling. C5a was purified from human yeast-activated plasma as described by Hugli et al. [14]. C5a was homogenous as shown by a single band on PAGE and on microzone electrophoresis at $\mathrm{pH}$ 8.6. The protein content was determined by amino acid analysis. Purified C5a was radiolabeled with ${ }^{125}$ I using a solid-phase lactoperoxidase-glucose oxidase method according to Hugli and Chenoweth [15]. The initial specific activity was 160 $\mathrm{Ci} / \mathrm{mmol}$.

Receptor assays. FML $\left.{ }^{3} \mathrm{H}\right] \mathrm{P}$ binding to PMNL was carried out at $4^{\circ} \mathrm{C}$ for $20 \mathrm{~min}$ using a silicon-oil technique as described previously $[2,16]$. For Scatchard analyses final concentrations of FML[ $\left.{ }^{3} \mathrm{H}\right] \mathrm{P}$ in binding assays varied from 3 to $200 \mathrm{nM}$. Nonspecific binding was determined with a parallel series of samples by adding a 1000 -fold excess of unlabeled FMLP. Scatchard plots of the experimental data (specific bindings) were fitted by linear regression. The dissociation constant $(\mathrm{Kd})$ and receptor number $\left(\mathrm{B}_{\max }\right)$ were estimated from the fitted slopes and $x$ intercepts [2]. ${ }^{125}$ I-C5a binding to PMNL was carried out at $4^{\circ} \mathrm{C}$ using a silicon-oil technique, similar to that described by Huey and Hugli [17]. The incubation time was $45 \mathrm{~min}$. For Scatchard analyses final concentrations of ${ }^{25} \mathrm{I}-\mathrm{C} 5 \mathrm{a}$ in binding assays were $0.08-20 \mathrm{n} M$. To determine the nonspecific binding, purified cold C5a was added to a parallel series of samples at a final concentration of $2.5 \mu M$. Nonspecific binding was routinely $<10 \%$.
The data were treated as described above. The specific activity of ${ }^{125}$ I-C5a was determined for each separate assay.

Measurement of cytosolic-free calcium $\left(\left[\mathrm{Ca}^{2+}\right]_{i}\right)$. Control and EAS-PMNL were loaded with quin 2-AM as follows: Cells were incubated in HBSS supplemented with glucose $(0.1 \%)$ at a concentration of $1 \times 10^{7} \mathrm{PMNL} / \mathrm{ml}$ with quin 2-AM at a final concentration of $1 \mu M$. Quin 2-AM was diluted 10-fold with $50 \%$ dimethyl sulfoxide/HBSS from a $2 \mathrm{~m} M$ stock solution in dimethyl sulfoxide before addition to PMNL. Quin 2 loading of PMNL was performed in a 30-min incubation with overhead rotation. Loading of 0.2-0.4 nmol of quin $2 / 10^{6}$ PMNL was obtained. After loading, cells were washed twice and resuspended in glucose-supplemented HBSS. Cells were diluted to $2.5 \times 10^{6} \mathrm{PMNL} / \mathrm{ml}$, maintained at room temperature, and protected from light until use. Control cells were incubated with an equivalent concentration of dimethyl sulfoxide and treated identically.

To determine the role of $\left[\mathrm{Ca}^{2+}\right]_{\mathrm{i}}$ in cellular priming, $\left[\mathrm{Ca}^{2+}\right]_{\mathrm{i}}$ was buffered with quin 2 in control experiments. For this purpose PMNL $\left(1 \times 10^{7} / \mathrm{ml}\right)$ were incubated $30 \mathrm{~min}$ in calcium-free HBSS $/ 0.1 \%$ glucose with quin 2-AM at a final concentration of $10 \mu \mathrm{M}$, which resulted in a loading of $2 \mathrm{nmol}$ of quin $2 / 10^{6} \mathrm{PMNL}$.

Fluorescent measurements were performed with a Perkin-Elmer fluorimeter (LS5; Perkin-Elmer) with two cutoff filters as described by Lew et al. [18]. The calculation of the loading and $\left[\mathrm{Ca}^{2+}\right]_{\mathrm{i}}$ was performed as described by Metcalf et al. [5].

$\left[\mathrm{Ca}^{2+}\right]_{1}$ dependency of $\mathrm{O}_{2}^{-}$production. To transiently increase $\left[\mathrm{Ca}^{2+}\right]_{\mathrm{i}}$, ionomycin (500 $\mathrm{nM}$ final concentration) was added to PMNL in calcium-free medium (mHBSS), as described by Lew et al. [19]. This increase was recorded with the quin 2 method. In concurrent experiments, FMLP-induced $\mathrm{O}_{2}^{-}$production was measured in identically treated PMNL at different intervals after the addition of ionomycin.

Statistics. As an estimate of variance, standard deviation of the mean was used in the text and tables and standard error in the figures. Means were compared by Student's $t$ test.

\section{Results}

Specific and primary granules in primed PMNL. Limited degranulation of specific granules is possibly one of the critical events in the cellular priming process. We therefore determined the content of specific and primary granules in PMNL preincubated either in HBSS $/ 0.1 \%$ glucose $/ 0.1 \%$ albumin or in $1.7 \%$ EAS or that had migrated through $5-\mu \mathrm{m}$ holes of a $10-\mu \mathrm{m}$ polycarbonate filter toward $1.7 \%$ EAS. Table 1 summarizes the results. Pretreatment of PMNL with $1.7 \%$ EAS and migration toward EAS induced a preferential loss of specific granules. The primary granule marker $\beta$-glucuronidase did not significantly differ in the three cell types.

Superoxide production. We next studied the effect of EAS preincubation on the subsequent $\mathrm{O}_{2}^{-}$production in response to FMLP and C5a. $\mathrm{O}_{2}^{-}$production was determined in the presence and absence of cytochalasin $B$, since pretreatment of PMNL with cytochalasin $B$ by itself enhances and prolongs the respiratory burst induced by FMLP and C5a [20]. Figure 1 shows the $\mathrm{O}_{2}^{-}$production rate in EAS-PMNL compared 
Table 1. Granule content of untreated (control) and pretreated polymorphonuclear leukocytes (PMNL).

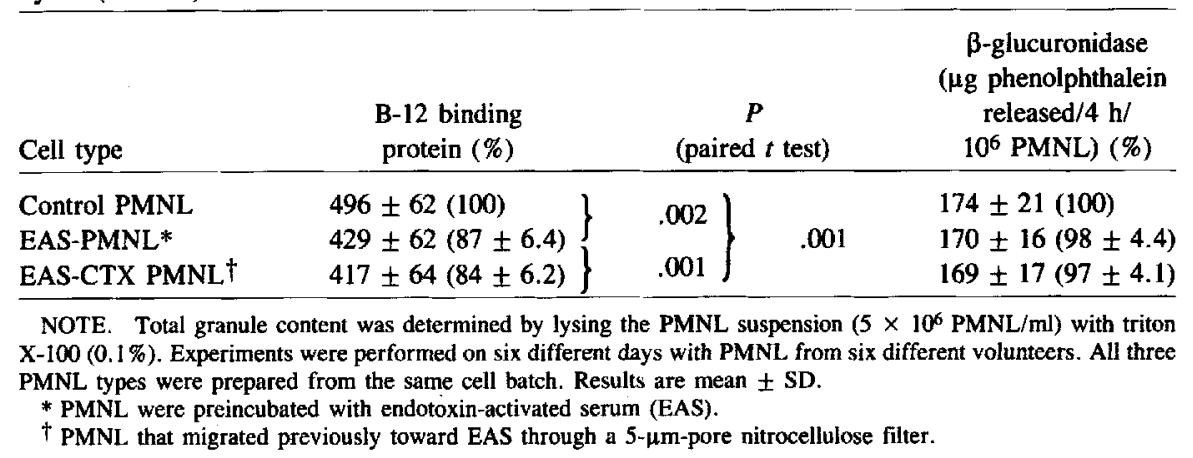

with control cells. Interestingly, when PMNL were stimulated with $10^{-6} M$ FMLP, the priming effect of EAS was observed only in the absence of cytochalasin B. However, at a submaximal concentration of FMLP $\left(10^{-7} \mathrm{M}\right)$ priming was observed both in the absence $\left(2.7 \pm 0.2\right.$ vs. $1.7 \pm 0.4 \mathrm{nmol}$ of $\mathrm{O}_{2}^{-}$ $\left.\mathrm{min} / 10^{6} \mathrm{PMNL} ; P<.05\right)$ and in the presence $(5 \pm 1.0 \mathrm{vs}$. $3.3 \pm 0.25 \mathrm{nmol}$ of $\left.\mathrm{O}_{2}^{-} / \mathrm{min} / 10^{6} \mathrm{PMNL} ; P<.05\right)$ of cytochalasin $\mathrm{B}$. The responsiveness of EAS-PMNL was also increased by stimulation with $10^{-7} M$ C5a (figure $1 \mathrm{~B}$ ), regardless of the presence of cytochalasin $\mathrm{B}$.

By preincubating PMNL with a substimulatory concentration of C5a $\left(10^{-9} M\right)$, their responsiveness toward FMLP
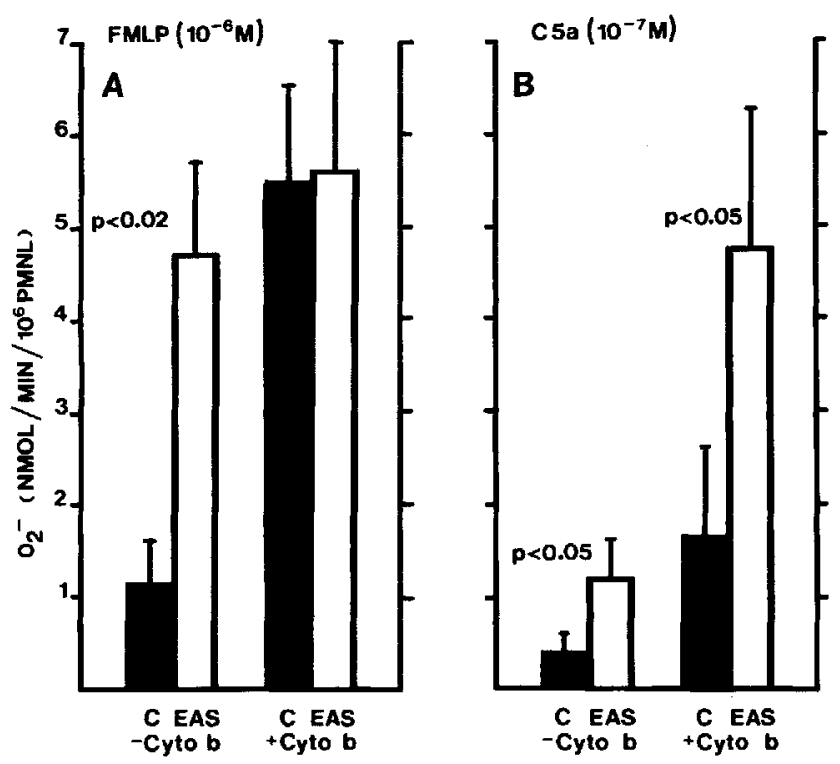

Figure 1. Superoxide production $\left(\mathrm{O}_{2}^{-}\right)$of blood polymorphonuclear leukocytes (PMNL) incubated $\left(37^{\circ} \mathrm{C}\right.$ for $\left.30 \mathrm{~min}\right)$ either in HBSS/ $0.1 \%$ glucose $/ 0.1 \%$ albumin (C) or in $1.7 \%$ endotoxinactivated serum (EAS). PMNL were washed twice before testing $\mathrm{O}_{2}^{-}$production. $\mathrm{A}$, Maximal initial rate in response to $10^{-6} \mathrm{M}$ formylpeptide (FMLP) in the presence or absence of cytochalasin B. $\mathrm{B}$, Corresponding results in response to $10^{-7} M \mathrm{C} 5$ a. Statistical analysis was performed by paired $t$ test. Results are means \pm SE of six different experiments. $\left(10^{-6} M\right)$ was increased $(5.0 \pm 0.6$ vs. $2.7 \pm 0.6 \mathrm{nmol}$ of $\left.\mathrm{O}_{2}^{-} / \mathrm{min} / 10^{6} \mathrm{PMNL} ; \boldsymbol{P}<.001\right)$. In contrast, the responsiveness toward cytochalasin B plus C5a $\left(10^{-7} M\right)$ decreased (1.1 \pm 0.6 vs. $2.0 \pm 1.2 \mathrm{nmol}$ of $\mathrm{O}_{2}^{-} / \mathrm{min} / 10^{6} \mathrm{PMNL} ; P<.05$ ).

Effect of different priming factors on FMLP- and C5ainduced membrane depolarization. Using the membrane depolarization assay, previously shown to be a convenient test to detect priming [13], we analyzed which component of EAS might be responsible for PMNL priming and whether migration influenced the priming process. Figure 2A shows that the response of PMNL previously incubated with EAS, C5a, or endotoxin, but not decomplemented plasma, was similarly enhanced toward $10^{-6} M$ FMLP, as was the response of PMNL which had previously migrated through a chemotactic filter. Priming did not result in a modified dose-dependency response; that is, the FMLP concentration leading to halfmaximal depolarization was similar between EAS- and control PMNL $\left(2 \times 10^{-8} \pm 1.4 \times 10^{-8} M\right.$ vs. $2.4 \times 10^{-8} \pm 1.3$ $\times 10^{-8} M$, respectively; $n=8$ pairs).

Figure 2B shows the membrane depolarization of different PMNL preparations in response to $10^{-8} M$ C5a. With this stimulus, the priming effect of EAS $(1.7 \%)$, C5a $\left(10^{-9} M\right)$ or endotoxin $(5 \mu \mathrm{g} / \mathrm{ml}$ ) was even higher, reaching between $170 \%$ (C5a) and $210 \%$ (EAS) above controls. However, the C5a concentration eliciting half maximal depolarization was somewhat higher in EAS-PMNL than in control cells $(4.3 \times$ $10^{-10} \pm 9.4 \times 10^{-11} M$ vs. $3.6 \times 10^{-10} \pm 9.4 \times 10^{-11} M$, respectively; $n=8$ pairs, $P<.05$ ). At a nondepolarizing concentration of C5a $\left(10^{-10} M\right)$ in the preincubation, the priming for $\mathrm{C} 5 \mathrm{a}\left(10^{-8} \mathrm{M}\right)$-induced membrane depolarization was in the same range, $159 \% \pm 7 \%$ of the control. Thus, in contrast to $\mathrm{O}_{2}^{-}$production, pretreatment with a low concentration of a stimulus identical to that used in the restimulation led to priming and not to deactivation of the membrane depolarization.

Requirements for priming. Priming by EAS was a rapid process. Figure 3 shows that it was detectable at $5 \mathrm{~min}$ and reached a plateau within $20 \mathrm{~min}$. The different requirements are summarized in table 2. Priming for FMLP-induced $\mathrm{O}_{2}$ production occurred at low concentrations of EAS; it was tem- 


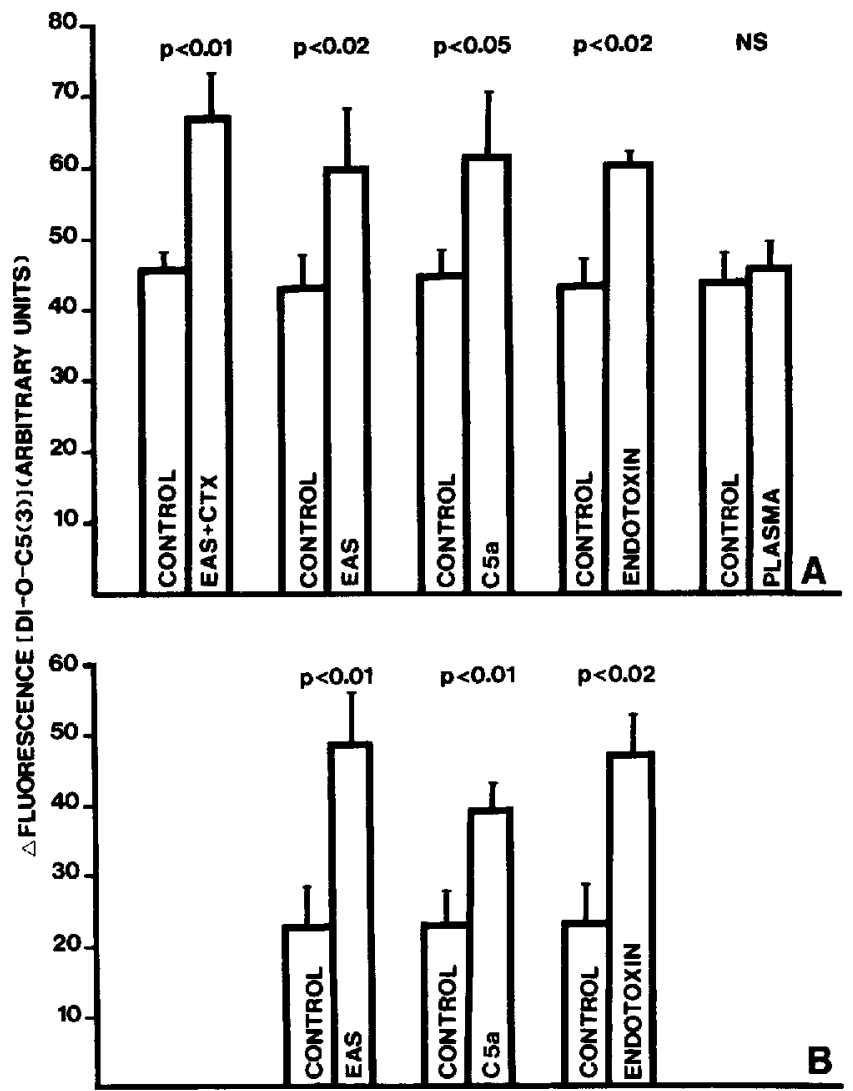

Figure 2. Effect of priming factors on $10^{-6} \mathrm{M}$ formylpeptide (FMLP)- (A) and 10-8 $M$ C5a- (B) induced membrane depolarization. Polymorphonuclear leukocytes (PMNL) were incubated for 30 $\mathrm{min}$ in either HBSS $/ 0.1 \%$ glucose $/ 0.1 \%$ albumin (control), $1.7 \%$ endotoxin-activated serum (EAS), purified C5a $\left(10^{-9} M\right)$, endotoxin $(5 \mu \mathrm{g} / \mathrm{ml})$, or decomplemented plasma $(1.7 \%)$. PMNL that had previously migrated through a chemotactic filter toward $1.7 \%$ EAS were labeled with EAS + CTX. PMNL were washed twice before testing membrane depolarization. Results are means \pm SE of 4-12 different experiments. Statistical analysis was performed by paired $t$ test.

perature dependent and required neither protein synthesis nor extracellular calcium. However, no priming was observed when intracellular calcium was buffered with quin 2 before incubation of PMNL with EAS in calcium-free buffer.

Mechanisms of priming. To determine whether the observed limited degranulation of specific granules increased receptor number, FMLP and C5a receptors were determined. Figure 4 shows that the number of FMLP receptors was 1.4fold higher in EAS-preincubated PMNL $(P<.05)$ but this was not accompanied by a significant alteration in affinity. Preincubation with endotoxin alone did not significantly increase FMLP receptors: $22,000 \pm 5400$ per control PMNL and $26,400 \pm 11,100$ per endotoxin-primed PMNL $(n=5$ pairs). Figure 5 shows that in cells, whether EAS primed or not, C5a receptors were similar in number and affinity under conditions in which the number of FMLP receptors was increased.

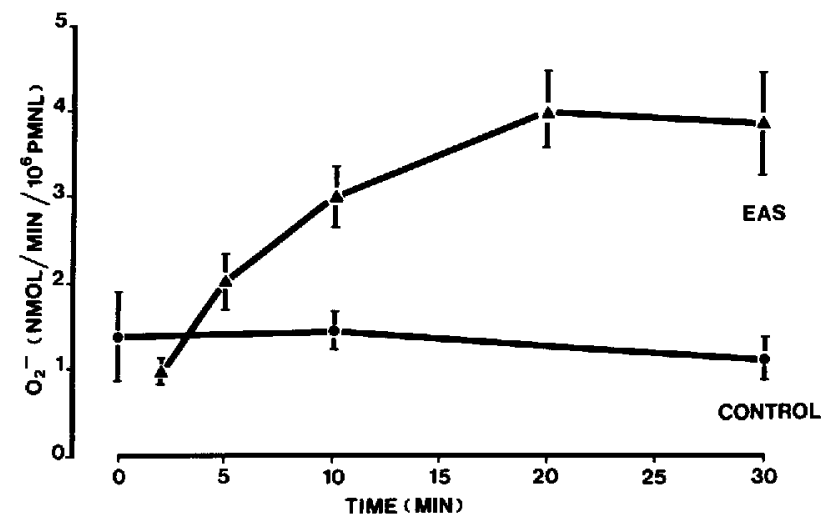

Figure 3. Influence of priming time on formylpeptide (FMLP)induced superoxide $\left(\mathrm{O}_{2}^{-}\right)$production. PMNL were incubated either in $\mathrm{HBSS} / 0.1 \%$ glucose $/ 0.1 \%$ albumin or in $1.7 \%$ endotoxin-activated serum. PMNL were diluted into ice-cold HBSS and washed twice at corresponding time points. Results are means $\pm \mathrm{SE}$ of triplicates from a representative experiment.

Table 2. Requirements for the priming process: $\mathrm{O}_{2}{ }^{-}$production rate in response to $10^{-6} M$ formyl peptide (FMLP) (nmol/min/ $10^{6} /$ PMNL).

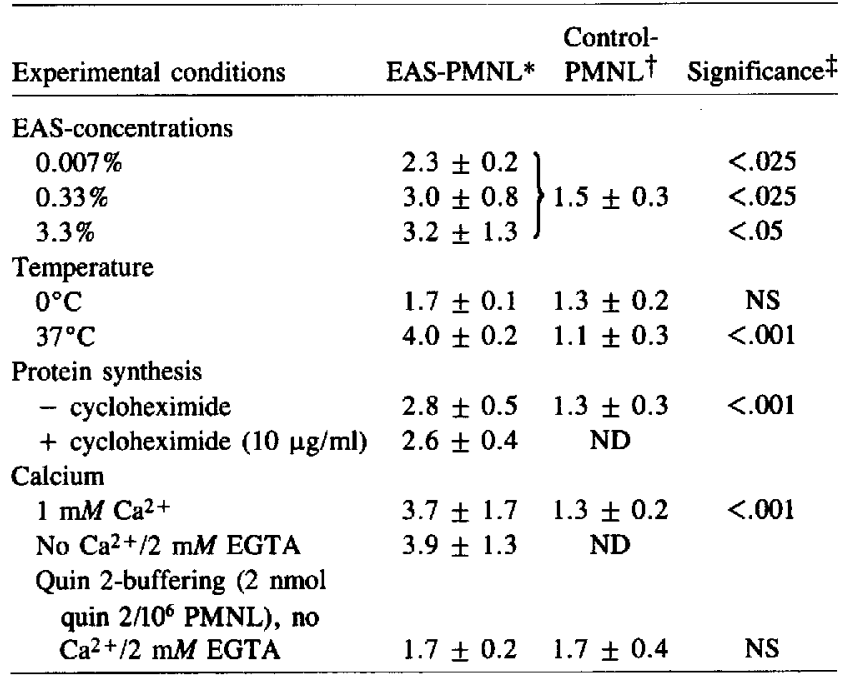

NOTE. EAS $=$ endotoxin-activated serum, $\mathrm{PMNL}=$ polymorphonuclear leukocytes. Each experiment was performed in triplicate at least three times.

* Incubation for $30 \mathrm{~min}$ with $1.7 \%$ EAS if not otherwise stated.

$\dagger$ Incubation for $30 \mathrm{~min}$ with $\mathrm{HBSS} / 0.1 \%$ glucose $/ 0.1 \%$ bovine serum albumin.

$\ddagger$ Comparison between control and EAS-PMNL (paired $t$ test): $P$ value; NS $=$ not significant.

As an alternative possible priming mechanism, we examined the intracellular calcium in primed and unprimed PMNL. Figure 6 shows that primed cells had a consistently higher "resting" $\left[\mathrm{Ca}^{2+}\right]_{\mathrm{i}}$ than control PMNL. This difference was significant $(P<.02)$ with cells isolated from five different donors.

To investigate whether an increased $\left[\mathrm{Ca}^{2+}\right]_{i}$ at the time of stimulation with an agonist can enhance the PMNL response, we measured the $\mathrm{O}_{2}{ }^{-}$production at different $\left.\left[\mathrm{Ca}^{2+}\right]\right]$ i concentrations. PMNL were pretreated with ionomycin to evaluate 

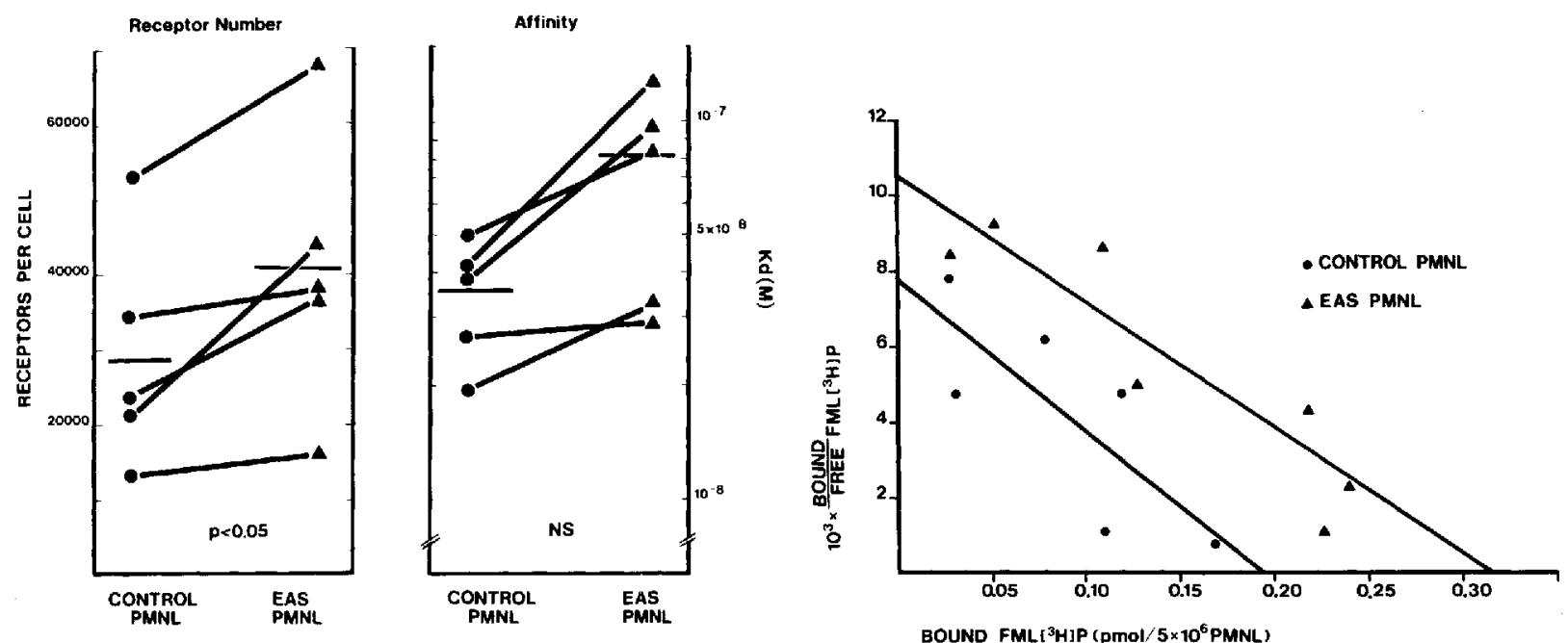

Figure 4. Total formylpeptide (FMLP) receptors per cell (left) and affinity constant (Kd) (middle). Polymorphonuclear leukocytes (PMNL) were preincubated and washed as described in Methods. Left and middle panels present results from Scatchard analyses performed on control and endotoxin-activated serum (EAS)-treated PMNL (pairs). Each pair represents an individual experiment. Significance of difference between means was determined by two-tailed Student's $t$ test. Right panel shows Scatchard plot of representative experiment with control and EAS-incubated PMNL.

the $\left[\mathrm{Ca}^{2+}\right]_{\mathrm{i}}$ and thereafter stimulated with FMLP at different intervals and levels of $\left[\mathrm{Ca}^{2+}\right]_{i}$. Figure 7 shows a good relationship between the $\left[\mathrm{Ca}^{2+}\right]_{\mathrm{i}}$ at the time of stimulation and the $\mathrm{O}_{2}^{-}$production rate that rose to values 2.2-4.2-fold above the baseline in five different experiments.

\section{Discussion}

It has been observed previously that PMNL modify their functional characteristics by sequential stimulation [16, 21-24].
These modifications are many and can be summarized as deactivation, adaptation, and priming. In our present study, we asked the following questions: Does EAS prime PMNL for FMLP- and C5a-induced functions? And, if so, which are the requirements for the EAS-induced priming? Also, what are the priming mechanisms?

By using highly purified C5a, we analyzed the effect of EAS prestimulation, even on cell functions that require high concentrations of the complement-derived chemotactic factor for stimulation. The use of C5a and FMLP allowed us to detect
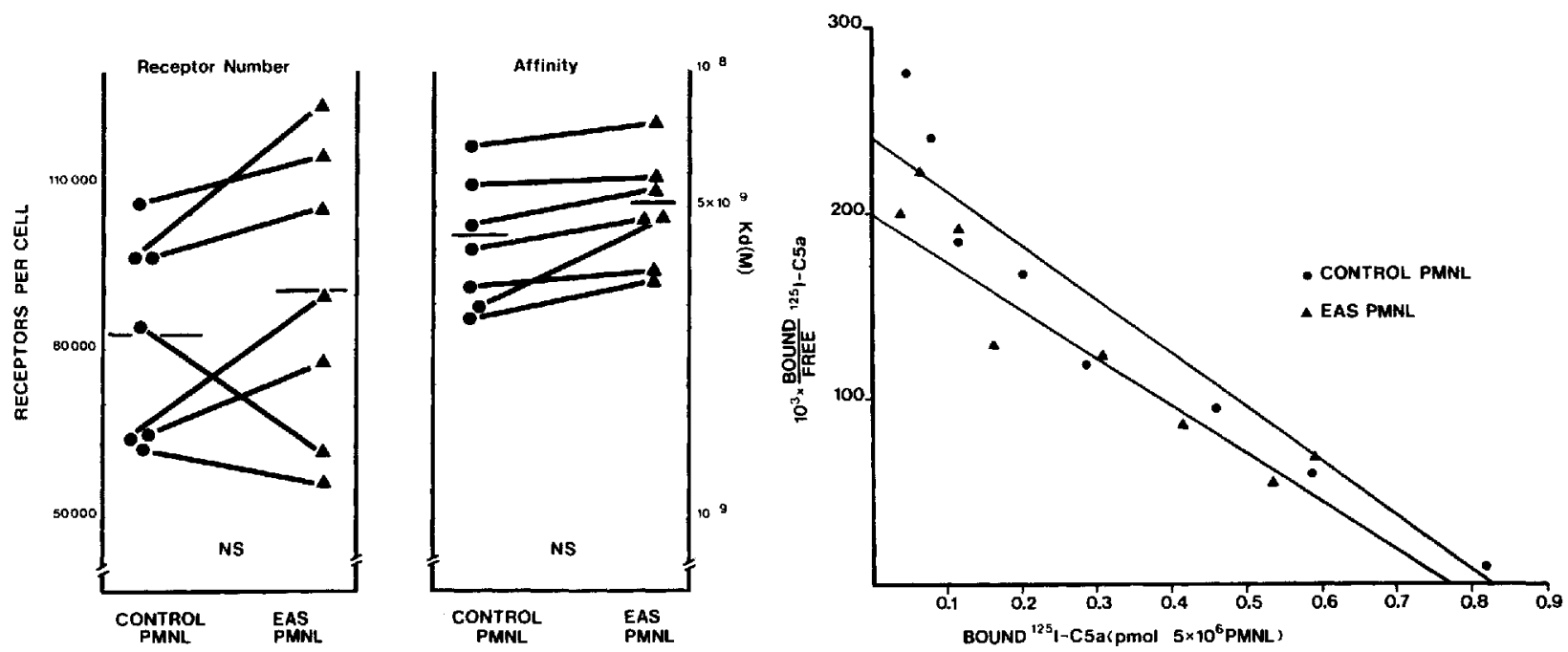

Figure 5. Total C5a receptors per cell (left) and affinity constant (Kd) (middle). Polymorphonuclear leukocytes (PMNL) were preincubated and washed as described in Methods. Left and middle panels present results from Scatchard analyses performed on control and endotoxin-activated serum (EAS)-treated PMNL (pairs). Each pair represents an individual experiment. Significance of difference between means was determined by two-tailed Student's $t$ test. Right panel shows Scatchard plot of representative experiment with control and EASincubated PMNL. 


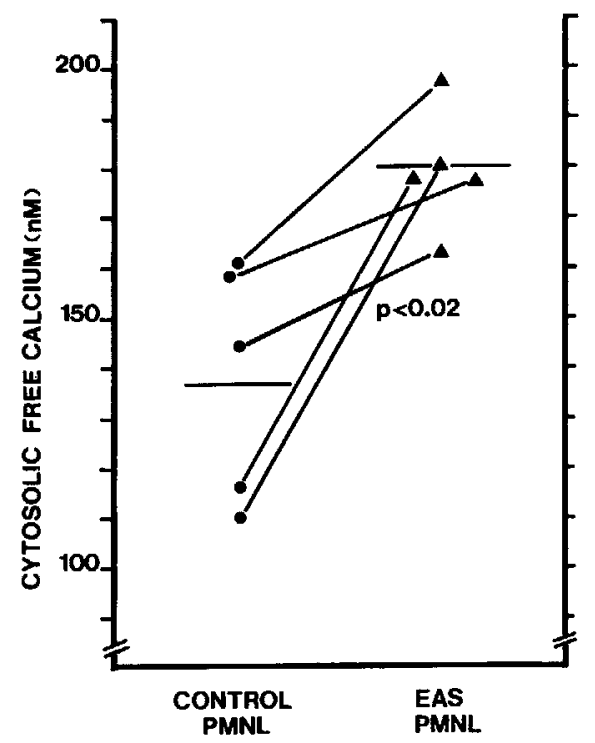

Figure 6. Resting cytosolic free calcium $\left(\left[\mathrm{Ca}^{2+}\right]_{\mathrm{i}}\right)$ in control and endotoxin-activated serum (EAS)-treated polymorphonuclear leukocytes (PMNL) (pairs). PMNL were preincubated and washed as described in Methods. $\left[\mathrm{Ca}^{2+}\right]_{\mathrm{i}}$ was determined in resting cells by the quin 2 method. Significance of difference between means was determined by two-tailed $t$ test.

possible discordant reactivity of EAS-PMNL, namely deactivation for one stimulus and priming for the other [2].

Control experiments confirmed that our PMNL preparations, isolated on a Percoll gradient, were not activated to a significant degree, since the priming was similar for PMNL prepared either in the presence or in the absence of polymyxin B. Further, significant priming with $<100 \mathrm{ng} / \mathrm{ml}$ endotoxin occurs only after an incubation of $>30 \mathrm{~min}$ [7].

EAS-pretreated PMNL had a lower residual content of specific granules than did control PMNL. This effect was even more pronounced in PMNL that had migrated through a filter in response to EAS. However, the enhancement of cellular responsiveness toward a second agonist was identical regardless of whether the cells had migrated, indicating that a larger degree of degranulation of secondary granules does not necessarily lead to a stronger priming.

In the presence of cytochalasin $\mathrm{B}$, priming was observed only with a submaximal concentration of FMLP $\left(10^{-7} M\right)$. This indicates that the respiratory burst was maximally stimulated by cytochalasin B and $10^{-6} M$ FMLP. PMNL preincubated with $10^{-9} M$ C5a showed a primed membrane depolarization but a deactivated $\mathrm{O}_{2}^{-}$production in response to C5a. This discrepancy remains unexplained and argues against a causal relationship between changes in membrane potential and subsequent oxidative burst.

The mechanisms of priming remain unknown. Many mediators, including low concentrations of $\mathrm{LTB}_{4}[25,26]$, 5-HETE [27], platelet activating factor [26, 28], FMLP [21, 22, 24], and C5a (as shown here), plus cytokines such as granulocyte-

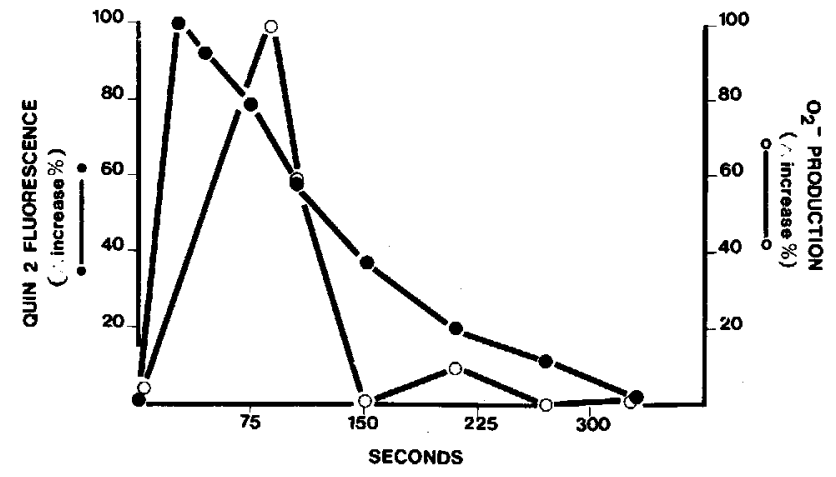

Figure 7. Representative experiment showing the dependency of superoxide $\left(\mathrm{O}_{2}^{-}\right)$production on $\left[\mathrm{Ca}^{2+}\right]_{i}$ in response to formylpeptide (FMLP). $\left[\mathrm{Ca}^{2+}\right]_{\text {i }}$ was transiently increased by adding ionomy$\operatorname{cin}(500 \mu M$ final concentration) to polymorphonuclear leukocytes (PMNL) in calcium-free medium (mHBSS) [13]. Changes in $\left[\mathrm{Ca}^{2+}\right]_{\mathrm{i}}$ were recorded with the quin 2 method. In concurrent experiments, FMLP-induced $\mathrm{O}_{2}^{-}$production was measured in identically treated PMNL at different intervals after the addition of ionomycin. Values of $100 \%$ represent the maximal increases for $\left[\mathrm{Ca}^{2+}\right]_{\mathrm{i}}$ and $\mathrm{O}_{2}{ }^{-}$ production above the baseline value. Experiments with PMNL from four other donors gave similar results.

macrophage colony-stimulating factor [29-32], tumor necrosis factor- $\alpha[33]$, and endotoxin $[10,11,28]$, have been shown to enhance the response triggered by a second agonist. Priming with EAS occurs rapidly (figure 3), whereas prolonged incubation is required for the action of lipopolysaccharide or cytokines $[7,10,11,28]$. Thus, the mechanism of priming by EAS might differ from that by cytokines and endotoxin.

Most priming agents such as chemotactic factors induce a limited degranulation of secondary granules and mobilize FMLP and C3bi receptors. It has been suggested that FMLPreceptor upregulation might be responsible for the enhanced responsiveness of PMNL $[2,16,34]$. We found an increase of FMLP receptors after preincubation of PMNL with EAS (figure 4) but not with endotoxin. Further, preincubation of PMNL with EAS did not result in an upregulation of C5a receptors. Since we demonstrated that priming does not result in an increased number or affinity of C5a receptors but still enhances a response triggered by $\mathrm{C} 5 \mathrm{a}$, mechanisms other than receptor upregulation must be operative in the priming process.

Forehand et al. [35] recently offered an explanation for the priming of PMNL with lipopolysaccharide. They found a 1.6fold increase of the resting $\left[\mathrm{Ca}^{2+}\right]_{i}$ in lipopolysaccharidetreated PMNL. We found a similar increase of the resting $\left[\mathrm{Ca}^{2+}\right]_{i}$ in PMNL primed with EAS. Finkel et al. [36] showed that increasing the $\left[\mathrm{Ca}^{2+}\right]_{i}$ of PMNL with ionomycin potentiated their oxidative burst in response to different stimuli. The positive association between the $\mathrm{O}_{2}^{-}$production rate and the $\left[\mathrm{Ca}^{2+}\right]_{i}$ at the time of stimulation with FMLP (figure 7) points out the relevance of the increased resting $\left[\mathrm{Ca}^{2+}\right]_{\text {i }}$ as priming factor. 
This proposed priming mechanism is compatible with the observed priming requirements (table 2 ). Since priming also occurred in the absence of extracellular calcium, the small increase of intracellular free calcium arises via mobilization from intracellular pools [37]. This is also supported by the lack of priming after buffering $\left[\mathrm{Ca}^{2+}\right]_{\mathrm{i}}$ with quin 2 . A similar observation was made by Forehand et al. [35], who could abolish the endotoxin-induced priming by MAPTAM, another intracellular $\mathrm{Ca}^{2+}$ chelator.

In conclusion, we demonstrated that EAS primes PMNL for both FMLP- and C5a-induced function without affecting $\mathrm{C5}$ a receptor number and affinity. Therefore receptor upregulation cannot be the priming mechanism for every stimulus. EAS-treated PMNL had an increased resting $\left[\mathrm{Ca}^{2+}\right]$, which may be responsible for their priming, since FMLP-induced $\mathrm{O}_{2}^{-}$production was increased in PMNL with a higher $\left[\mathrm{Ca}^{2+}\right]_{1}$ at time of stimulation and EAS did not prime PMNL in which $\left[\mathrm{Ca}^{2+}\right]_{\text {i }}$ was buffered during preincubation.

\section{Acknowledgment}

We thank Zuzana Kante for secretarial assistance and Dr. Regine Landmann for determination of endotoxin.

\section{References}

1. Malech HL, Gallin JI. Current concepts: immunology. Neutrophils in human diseases. N Engl J Med 1987;317:687-694

2. Zimmerli W, Seligmann B, Gallin J. Exudation primes human and guinea pig neutrophils for subsequent responsiveness to the chemotactic peptide $N$-formylmethionylleucylphenylalanine and increases complement component C3bi receptor expression. J Clin Invest 1986;77:925-933

3. Cline MJ. A new white cell test which measures individual phagocyte function in a mixed leukocyte population. I. A neutrophil defect in acute myelocytic leukemia. J Lab Clin Med 1973;81:311-316

4. Yuo A, Kitagawa S, Okabe T, Urabe A, Komatsu Y, Itoh S, Takaku F. Recombinant human granulocyte colony-stimulating factor repairs the abnormalities of neutrophils in patients with myelodysplastic syndromes and chronic myelogenous leukemia. Blood 1987;70:404-411

5. Metcalf JA, Gallin JI, Nauseef WM, Root RK. Laboratory manual of neutrophil function. New York: Raven Press, 1986

6. Zimmerli W, Lew PD, Waldvogel FA. Pathogenesis of foreign body infection. Evidence for a local granulocyte defect. J Clin Invest 1984; 73:1191-1200

7. Guthrie LA, McPhail LC, Henson PM, Johnston RB Jr. Priming of neutrophils for enhanced release of oxygen metabolites by bacterial lipopolysaccharide: evidence for increased activity of the superoxide-producing enzyme. J Exp Med 1984;160:1656-1671

8. Dahinden C, Galanos C, Fehr J. Granulocyte activation by endotoxin. I. Correlation between adherence and other granulocyte functions, and role of endotoxin structure on biologic activity. J Immunol 1983;130:857-862

9. Dahinden C, Fehr J. Granulocyte activation by endotoxin. II. Role of granulocyte adherence, aggregation, and effect of cytochalasin B, and comparison with formylated chemotactic peptide-induced stimulation. J Immunol 1983;130:863-868

10. Haslett C, Guthrie LA, Kopaniak MM, Johnston RB Jr, Henson PM. Modulation of multiple neutrophil functions by preparative methods or trace concentrations of bacterial lipopolysaccharide. Am J Pathol 1985;119:101-110

11. Wright GG, Read PW, Mandell GL. Lipopolysaccharide releases a priming substance from platelets that augments the oxidative response of polymorphonuclear neutrophils to chemotactic peptide. J Infect Dis 1988;157:690-696

12. Bannatyne RM, Harnett NM, Lee KY, Biggar WD. Inhibition of the biologic effects of endotoxin on neutrophils by polymyxin B sulfate. J Infect Dis 1977;136:469-474

13. Zimmerli W, Seligmann BE, Gallin JI. Neutrophils are hyperpolarized after exudation and show an increased depolarization response to formyl-peptide but not to phorbol myristate acetate. Eur J Clin Invest 1987;17:435-441

14. Hugli TE, Gerard C, Kawahara M, Scheetz ME II, Barton R, Briggs S, Koppel G, Russell S. Isolation of three separate anaphylatoxins from complement-activated human serum. Mol Cell Biochem 1981: 41:59-66

15. Hugli TE, Chenoweth DE. Biologically active peptides of complement: techniques and significance of C3a measurements in immunoassays. In: Nakamura RM, Dito WR, Tucker ES III, eds. Clinical laboratory techniques for the 1980's. New York: Alan R Liss, 1980:443

16. Fletcher MP, Seligmann BE, Gallin JI. Correlation of human neutrophil secretion, chemoattractant receptor mobilization, and enhanced function capacity. J Immunol 1982;128:941-948

17. Huey $\mathrm{R}$, Hugli TE. Characterization of a C5a receptor on human polymorphonuclear leukocytes (PMN). J Immunol 1985;135:2063-2068

18. Lew PD, Wollheim CB, Waldvogel FA, Pozzan T. Modulation of cytosolicfree calcium transients by changes in intracellular calcium-buffering capacity: correlation with exocytosis and $\mathrm{O}_{2}{ }^{-}$-production in human neutrophils. J Cell Biol 1984;99:1212-1220

19. Lew PD, Monod A, Waldvogel FA, Dewald B, Baggiolini M, Pozzan T. Quantitative analysis of the cytosolic free calcium dependency of exocytosis from three subcellular compartments in intact human neutrophils. J Cell Biol 1986;102:2197-2204

20. Dahinden CA, Fehr J, Hugli TE. Role of cell surface contact in the kinetics of superoxide production by granulocytes. J Clin Invest 1983; 72:113-121

21. English D, Roloff JS, Lukens JN. Regulation of human polymorphonuclear leukacyte superoxide release by cellular responses to chemotactic peptides. J Immunol 1981;126:165-171

22. English D, Roloff JS, Lukens JN. Chemotactic factor enhancement of superoxide release from fluoride and phorbol myristate acetate stimulated neutrophils. Blood 1981;58:129-134

23. Bender IG, van Epps DE. Stimulus interactions in release of superoxide anion $\left(\mathrm{O}_{2}^{-}\right)$from buman neutrophils. Further evidence for multiple pathways of activation. Inflammation 1985;9:67-79

24. Van Epps DE, Garcia ML. Enhancement of neutrophil function as a result of prior exposure to chemotactic factor. J Clin Invest 1980; 66:167-175

25. Gay JC, Beckman JK, Brash AR, Oates IA, Lukens JN. Enhancement of chemotatic factor-stimulated neutrophil oxidative metabolism by leukotriene $B_{4}$. Blood 1984;64:780-785

26. Dewald B, Baggiolini M. Activation of NADPH oxidase in human neutrophils. Synergism between FMLP and the neutrophil products PAF and LTB4. Biochem Biophys Res Commun 1985;128:297-304

27. Badwey JA, Robinson JM, Horn W, Soberman RJ, Karnovsky MJ, Karnovsky ML. Synergistic stimulation of neutrophils. Possible involvement of 5-hydroxy-6,8,11,14-eicosatetraenoate in superoxide release. J Biol Chem 1988;263:2779-2786

28. Worthen GS, Seccombe JF, Clay KL, Guthrie LA, Johnston RB Jr. The priming of neutrophils by lipopolysaccharide for production of intracellular platelet-activating factor. Potential role in mediation of enhanced superoxide secretion. I Immunol 1988;140:3553-3559 
29. Dahinden CA, Zingg J, Maly FE, de Weck AL. Leukotriene production in human neutrophils primed by recombinant granulocyte/macrophage colony-stimulating factor and stimulated with the complement component C5a and FMLP as second signals. J Exp Med 1988;167: 1281-1295

30. Lopez AF, Williamson DJ, Gamble JR, Begley CG, Harlan JM, Klebanoff SJ, Waltersdorph A, Wong G, Clark SC, Vadas MA. Recombinant human granulocyte-macrophage colony-stimulating factor stimulates in vitro mature human neutrophil and eosinophil function, surface receptor expression, and survival. J Clin Invest 1986;78: $1220-1228$

31. Zimmerli W, Zarth A, Gratwohl A, Nissen C, Speck B. Granulocytemacrophage colony-stimulating factor for granulocyte defects of bone marrow transplant patients [letter]. Lancet 1989;1:494

32. Weisbart RH, Kwan L, Golde DW, Gasson JC. Human GM-CSF primes neutrophils for enhanced oxidative metabolism in response to the major physiological chemoattractants. Blood 1987;69:18-21

33. Atkinson YH, Marasco WA, Lopez AF, Vadas MA. Recombinant human tumor necrosis factor- $\alpha$ : Regulation of $N$-formylmethionylleucylphenylalanine receptor affinity and function on human neutrophils. J Clin Invest 1988;81:759-765

34. Weisbart RH, Golde DW, Gasson JC. Biosynthetic human GM-CSF modulates the number and affinity of neutrophil f-Met-Leu-Phe receptors. I Immunol 1986;137:3584-3587

35. Forehand JR, Pabst MJ, Phillips WA, Johnston RB Jr. Lipopolysaccharide priming of human neutrophils for an enhanced respiratory burst. J Clin Invest 1989;83:74-83

36. Finkel TH, Pabst MJ, Suzuki H, Guthrie LA, Forehand JR, Phillips WA, Johnston RB Jr. Priming of neutrophils and macrophages for enhanced release of superoxide anion by the calcium ionophore ionomycin. Implications for regulation of the respiratory burst. J Biol Chem 1987;262:12589-12596

37. Volpe P, Krause KH, Hashimoto S, Zorzato F, Pozzan T, Meldolesi J, Lew DP. "Calciosome," a cytoplasmic organelle: the insositol 1,4,5trisphosphate-sensitive $\mathrm{Ca}^{2+}$ store of nonmuscle cells? Proc Natl Acad Sci USA 1988;85:1091-1095 